\title{
Teaching and inculcating (decolonised) legal skills in the LLB curriculum at the University of Pretoria?
}

\section{Anton Kok}

University of Pretoria

Michelle Oelofse

University of Pretoria
Journal of Decolonising Disciplines

Volume 2, Issue 1 (2020)

eISSN: 2664-3405

DOI: https://doi.org/10.35293/jdd.v2i1.37

\section{Abstract}

'Legal Skills' was taught as a standalone first-year module in the LLB curriculum at the University of Pretoria from 1998 to 2012. In the 2013 curriculum, the teaching and inculcation of legal skills were integrated into a first-year "Jurisprudence" module. The 2015/6 student protests at the University of Pretoria led to the creation of three 'transformation work streams', one of which was tasked with curriculum transformation. The activities of the curriculum transformation work stream led to the adoption by the Senate of a Curriculum Transformation Framework Document (CTFD). All faculties have been asked to reconsider and fundamentally reshape their curricula with reference to the CTFD. This reflection-on-the-curriculum process at the Faculty of Law has arguably been dominated by an over-emphasis on the place and sequencing of modules instead of an overhaul of the content of law modules and the approach with which teaching should take place. There has also been a concerted push from some quarters in the Faculty to reintroduce a standalone Legal Skills module, rationalised by an argument along the lines of 'legal skills cannot be transformed' (never mind 'decolonised'). In this article we will consider what it could mean to ask for the decolonising of the teaching and inculcation of legal skills in an LLB curriculum. 


\section{Introduction}

Mbembe argues that South African tertiary education is trapped at 'the centre of the knot'; that it is disconnected from social realities such as poverty, high unemployment and disease, to the benefit of science and technology, with the belief that market capitalism will solve all problems (Mbembe 2012). This entrapment follows from a formalistic apartheid-era approach to law and politics. Apartheid's approach to legal education, teaching black letter law in the form of cases and legislation as the only acceptable method to understand law, is a system of self-reference to the exclusion of modern African practices (Modiri 2013) .

Universities seemed to keep students (and academics) on this leash successfully, encouraging silence within the 'knot', until the 2015 student protests across the country's university campuses. Modiri argues that these protests came about with students' realisation of (and being fed up with) with what he describes as 'the unresolved histories of universities' including their complicity in colonial racism and maintenance of class hierarchies (Modiri 2016).

In an earlier Mail and Guardian article, tertiary students' discomfort is summarised as students being taught a world, space and time that is not familiar to them and as a result student struggle to address their own realities, including socioeconomic struggles (Delport \& Dlada 2013).

The 2015 \#FeesMustFall protests went further than financial access to universities; calls were also made for decolonised curricula and at the University of Pretoria \#AfrikaansMustFall protests also followed.

In this article, we accept that South African universities remain 'frozen in positivistic time; and we tentatively look for paths out of colonial tertiary education, focusing on the teaching of legal skills in an LLB curriculum (Sachs 2008: 37).

In the recent past, all law faculties at public universities in South Africa had to grapple with the content of their law modules and their approach to legal education in light of the review of all LLBs by the Council for Higher Education (CHE). The accreditation panels visited the various faculties in 2016 - a time when many universities also experienced student protests. At the University of Pretoria, one of the outcomes of these protests was the establishment of three transformation workstreams - one on the language policy, one on curriculum transformation and one on institutional and residential culture. The workstream process relating to curriculum transformation culminated in the adoption by the Senate of a Curriculum 
Transformation Framework Document (CTFD). In terms of the CTFD, all faculties had to revisit their offerings. The Law Faculty had received an unconditional reaccreditation by the CHE, but a number of observations on the UP LLB were made by the accreditation panel in its report. The Faculty decided to undertake a significant overhaul of the LLB in light of these observations and the demands placed on it by the CTFD. ${ }^{1}$ During this process, some ideological tensions came to the fore. One of these tensions revolved around the purpose of legal education at a university and which skills should be inculcated during this education.

In this article we offer a few tentative observations on the terminology being used in recurriculisation efforts and then specifically consider how the inculcation of legal skills could be conducted in a transformed/decolonised LLB curriculum at the University of Pretoria.

We are both of white, middle-class status and have Afrikaans as our home language. These characteristics may have some bearing on how we view this debate and how this contribution will be received. We accept the risks that accompany putting pen to paper on this debate but still hope that this contribution will be received as a bona fide attempt to make a tentative and constructive contribution to the project.

1 The Faculty of Law's curriculum transformation implementation plan lists the following documents that all imply some measure of curriculum renewal: The CTFD, the UP 2025 plan that asks for rationalising of modules; the adoption of an inquiry-led curriculum; and a researchintensive university; a South African Law Deans (SALDA), Law Society of South Africa (LSSA) and Attorney's Fidelity Fund (AFF) policy document on Legal Ethics in the LLB curriculum; a SALDA and LSSA policy document on Information and Communication Technology Law in the LLB curriculum; the CHE national standards for the LLB; the outcome of the CHE review of all South African LLB curricula, in particular the CHE report on the UP LLB and the CHE national report on legal education in South Africa; a SALDA project on a decolonised/Africanised LLB (to be completed); UP's drive to implement a hybrid approach to teaching and learning and assessment; HEQSF (for the provision of Level Descriptors, Exit Level Outcomes and Qualification Registration document); and the United Nations Sustainable Development Goals. 


\section{Tentative observations on terminology: Decolonisation, Indigeneity, reform, transformation, Africanisation}

Before investigating the how of decolonising a curriculum, it is important to understand the origins of the concept. For this purpose, postcolonial studies may be useful. The term postcolonialism was first used by sociologists and political scientists as an adjective to describe former African and Asian colonies after the Second World War, with the term 'dependency' used in Latin American literature when describing their formal colonial status (Nayar 2015).

Siu, Desai and Ritskes (2012) compiled the 2012 inaugural issue of Decolonization: Indigeneity, education \& society. In the foreword of the compilation they summarised the many definitions of decolonisation they came across as 'messy, dynamic and ... contradictory' (Siu et al. 2012). The authors, however, agree that decolonisation centres Indigenous methods and peoples and that the manifestation of it is found in the constant negotiation of power, place, identity and sovereignty.

Dladla links transformation of the curriculum to decolonisation in the following manner:

Curriculum transformation and more particularly, epistemic decolonisation is part of the pursuit of historical justice in its endeavour to reverse the material as well as epistemological and cultural effects of colonisation and white supremacy.(Dladla 2012)

It is clear that, for Dladla, decolonisation links with the reversal of historical injustice, which is taking it a step further than placing Indigenous communities' knowledge at the centre of the transformation that is sought.

If Indigenous knowledge informs decolonisation, the question follows: What is Indigenous knowledge? Siu et al. (2012) answers that this epistemology is a way of living that is so deeply embedded in the lives of people that it cannot be codified, or even defined. In a South African context this would accordingly refer to, at least, living customary law. ${ }^{2}$

2 The Constitution (of the Republic of South Africa, 1996) recognises customary law as a system of law applied by the courts, s 211, subject only to the Constitution itself. The notion of living customary law has been recognised by the Constitutional Court in, amongst other cases, Bhe and Others v Khayelitsha Magistrate and Others 2005 (1) SA 580 (CC). 
Himonga and Diallo (2017) investigate curriculum decolonisation with reference to living customary law. They describe this process using three elements: the inclusion of living customary law in legal education, a paradigm shift in legal theory and the interdisciplinary study of law (Himonga \& Diallo 2017). In addressing the first element, it is of importance to note that customary law should not be studied in isolation, but should rather be a part of the core curriculum of legal education (Himonga \& Diallo 2017).Secondly, a shift must be made from legal centralism/ positivism, because living customary law cannot be studied in the abstract, away from its social contexts. Such a departure may be achieved though legal education focusing on the theoretical perspective of legal pluralism (Himonga \& Diallo 2017). Lastly, taking effort to study law together with other social sciences, especially history, will provide a better understanding of law as a tool to decolonise society in a larger sense.

In referring to indigeneity in relation to decolonisation, the following caveat is provided by Max Price and Russel Ally (2015: 23): "decolonisation ... should certainly not be reduced to some naïve ... desire to return to a pristine, unblemished Africa before the arrival of the settlers". This addresses, in our opinion, the claims to create a world, and legal system, as if untouched by colonial powers. Drawing on the three-elements model developed by Himonga and Diallo (2017),(mentioned above) we contend that a conscious interaction with colonial heritage is required, as such a confrontation is a necessary part of moving towards legal pluralism that also explicitly includes customary law in its various forms.

Concerning the relation between colonies and nations attempting decolonisation, Siu et al. (2012) make the observation that decolonisation (and Indigeneity) is not reactionary or bound to colonial power but also state that decolonisation is opposite to a colonial way of doing things. These definitions, read together, have no obvious middle ground.

Nayar (2015) offers an explanation for this contradiction, making the observation that adding the words "post" and "colonial" in "postcolonial studies" creates a grammatical juxtaposition. Here "post" provides a temporal marker indicating the problematic classification of societies in history and it evokes the epistemological problem of knowledge of history and society, understood in relation to imperial rule (Nayar 2015).

Following Nayar's (2015) logic, decolonising a curriculum puts one in the position of looking at history through a colonial lens. Decolonising might, in 
accordance with this understanding, not be a neutral way of building a curriculum where an African way of thinking is central. Building a curriculum in this way may lead to two, divergent, conclusions. The first is that transformation, reformation or Africanisation may be more appropriate terms to describe the change in curricula that academics are calling for, moving away from the classification of information that is either colonial or not, because it may be found that certain western concepts, coined 'colonial;, may overlap with African pursuits. Secondly, describing this change of curricula as 'decolonising' might indicate the preference of having the word 'colonial' as a visual cue of what must be discarded. Reflecting on the works of African academics, it seems that the latter option was (at least at an unconscious level) chosen in order to facilitate this change.

In 1991, Collins wrote about the experience of African-American women in academia. Collins (1991) advocated a decentring of curricula containing ideas and experiences of elite white men. She investigated several theories, including that of curriculum transformation as described by Peggy MacIntosh's phase-theory model. The phases may be summarised as follows (Collins 1991):

1. The womanless curriculum;

2. Women in the discipline;

3. The absence of women in the curriculum as a problem;

4. Women on their own terms centring their experiences;

5. An inclusive curriculum.

One critique of the phase-theory models, one of which is as illustrated above, is that it is simply reformist. The theories seem simply to describe existing approaches to curriculum change and not how change should occur, which would be more in line with a transformative approach (Collins 1991).

Following this model in a South African context would support the idea that decolonisation/transformation already took place in the everyday lives of South Africans, but universities are lagging behind in the knowledge they teach. Calling for transformation, accordingly, could indicate that we have reached the fourth phase, where Africans are contributing to the academic conversation on their own terms, using their experiences as a point of reference - and indeed, we see writers such as Modiri, Mbembe, Murungi and Ramose contributing to the current conversation on transforming tertiary curricula. 
Collins (1991) employed a 'Race on Campus: Applying Theory in Everyday Life' assignment to make students more aware of race relations on their campus. This assignment was designed to place historically marginalised groups at the centre of analysis, and to open up new approaches to knowledge (Collins 1991). The assignment, according to Collins (1991), illustrates reconstructed knowledge through self-defined standpoints, with dialogue as the main go-between. The conclusion reached by the students - a class of 25, half of whom are black and the other half white - seems to be a realisation of white privilege on the one hand, and on the other hand of the subordinate status of black people in society. This was an exercise in dialogue that led to the recognition of racial order, a conversation on how this order was the consequence of one historical system and, lastly, how this order affects individuals.

In January 2006, the Bolivian government announced the 'politics of change' project promoting their 'twenty-first-century socialism' political ideology, to transform Bolivian politics, economy and society (Cadozo 2012). Included in this initiative, approved in December 2010, is the decolonisation of the entire education system, taking the strong stance that 'teachers are soldiers of the liberation and decolonisation of Bolivia' (Cardozo 2012).

Four pillars were identified in describing the ideological underpinnings of the restructuring of the education system: decolonisation, intra- and interculturalism along with plurilingualism, productivity and communitarian education. Concerning decolonisation, the Bolivian Department of Education formally defined it as putting all races on equal footing with regard to the area of education, work, politics and economic security and at the same time valuing the skills, knowledges and technologies of indigenous peoples (Cardozo 2012).

Modiri (2016) makes the argument, based on Freire's 'narration sickness' idea, that South African students are passive learners, narrated to by lecturers disconnected from reality. This idea, where a teacher narrates reality, as if it is motionless and predictable, leads to students that are disconnected from reality.

If law students, in accordance with the above, are expected to receive information (the black letter law) and memorise and regurgitate the same information for tests, one consequently produces legal practitioners with no insight into the law as a tool of power, oppression and/or transformation.

Freire's (1970) suggestion is to focus on the problem faced by education, where the process of education is described as an 'unfinished reality'. Finding ourselves in a 
post-apartheid era, legal education and indeed the content of law should reflect this reality, acknowledging that it is still in a constant state of flux.

Linked to the 'narration' quandary is the what of the narration aimed at students. Zegeye and Vambe (2011) make the argument that South African universities are in the grip of a Northbound gaze', looking towards the North, and in more particular terms Europe, for theoretical approval of work and assumptions. A change of gaze, away from colonial powers, would address the narration of what is strange and foreign to African legal students.

If it may be assumed that decolonisation of tertiary curricula is a conscious process, the question of responsibility arises: who needs to take the initiative in instigating and following through the decolonisation of curricula? One to-be-expected answer would be that an authoritative body representing (Indigenous) people must do this perhaps the government as the representative of the peoples who were marginalised by the colonising powers. But if it is also true that the government and academia were institutions of colonial power, is it accordingly possible not only to decolonise the institutions itself, but to decolonise through them (Siu et al. 2012)?

The next problem we encountered in literature on decolonisation is the reference to 'decolonising the mind' ( $\mathrm{N}$ wa Thiong' 1986). This specific phrase might lead to the containment of decolonisation to academia and conferences, failing to recognise the real, physical effects of (de)colonisation of the everyday lives of peoples (Siu et al. 2012). Regarding the decolonisation of legal skills, specifically at the University of Pretoria, we attempt to give decolonisation a 'real-world' manifestation, being conscious of the fact that theory and action are interlocking, that theory must inform action and action must inform theory (Siu et al. 2012).

McLaughlin and Whatman (2008) contend that non-Indigenous academics, who often happen to be in control of the parameters in a transformation process, can only 'see' Indigenous knowledge from their colonial worldview. It would accordingly be essential that decolonisation is driven and guided by black academics in the South African context.

Modiri (2016) contends that critical legal education is aimed at delivering skilled graduates who are also critically literate. Such an education must attend to a subversive orientation towards history, practice and theory; problematise constitutional fetishism; and decolonise and transform the LLB curriculum Modiri 2016).

The concept of subversion is of particular interest as this speaks to the real-world 
application of legal education or, in other words, legal skills. Visser (1989) comments that the subversive method illustrates that the principles of law not only function in academic textbooks, but that they are created by people (in particular contexts) to have an effect on other people - the importance of subversion thus is to make students aware of the practical effects of law. This method of teaching is in direct contrast to apartheid legal education which saw law as an independent, innocent entity that may not be questioned (Modiri 2016).

\section{Curriculum transformation at the Faculty of Law at the University of Pretoria}

The CTFD alluded to in the introduction does not contain any references to decolonisation or decoloniality. The document employs 'transformation'. The CTFD lists four drivers of curriculum transformation: responsiveness to social context; epistemological diversity; renewal of pedagogy and classroom practices; and an institutional culture of openness and critical reflection. The four drivers are then unpacked in the document. Elements contained in this unpacking seem to hint at decolonisation, or at least a decolonial approach to curriculum content and approach to teaching. For example, 'responsiveness to social context' includes 'retrieving and foregrounding historically and presently marginalised narratives, voices and subjugated knowledges ... as creating new forms of telling, being and becoming' and 'acknowledging indigenous knowledge systems hitherto repressed in the South African context.' 'Epistemological diversity' includes 'bringing marginalised groups, experiences, knowledges and worldviews emanating from Africa and the Global South to the centre of the curriculum', and 'Excavating and recuperating African, Latin American and Asian knowledges and practices that have been devalued and marginalised and, in some cases, decimated and distorted by US and European centrism and epistemic racism and sexism'.

In terms of the CTFD, each Faculty had to develop a curriculum transformation implementation plan. The Faculty of Law's plan was a somewhat contested document and in an attempt to placate vocal opponents of some elements of the plan, the language used in the plan was modest and subtle. The only part of the plan that speaks directly to the CTFD is a list of questions that the various academic departments in the Faculty should have used to reflect on the content of their modules: What is the appropriate balance in a particular module (and in the LLB as a whole that should be more than the sum of its parts) between the basic principles/core content 
of that module and broader socio-political considerations - how much of what in each module (basic knowledge, skills, values); to what extent should the LLB deal explicitly with the law's ability or inability to facilitate societal transformation and address contemporaneous South African challenges: access to justice; poverty; the huge disparities in wealth and income and power; etc; how should the revised content of the modules acknowledge that law is central to creating a cohesive and successful society, how it plays a significant role in facilitating economic development and most importantly, how it is pivotal to entrenching the ethos and values of the country's constitutional democracy; how can every module reiterate the fundamental understanding that legal education as a public good should be responsive to the needs of the economy, the legal profession and broader society; how should the UP LLB produce skilled graduates with a profound understanding of the impact of the Constitution on the development of the law, and advancing the course of social justice in South Africa; how should UP law graduates be equipped to discharge their social and professional duties ethically and efficaciously; to what extent should the UP LLB equip students to be able to utilise the qualification they obtain as a professional qualification and career; to what extent should different approaches in law to address particular social phenomena be made explicit; to what extent should a particular lecturer make her approach to legal education, to law, to the relationship between law and society, explicit; in classroom teaching, how should students be encouraged to share examples from their own experiences that can be used in class to show how the law is relevant to concrete South African problems, and how it could be used or developed to solve these problems, if possible? These questions did not get much traction in the Faculty when considering changes to content or approach to teaching in law modules.

At the time of finalising this article (August 2019), the curriculum transformation process had been halted temporarily, awaiting the appointment of a new dean. Valuable initial reflective exercises were undertaken by some colleagues, and a number of Faculty workshops were held where some valuable contributions have been made, but on the whole significant differences of opinion exist on the direction that the UP LLB renewal process should take. The UP LLB curriculum for 1998-2012 included two stand-alone Legal Skills modules in the first semester in which firstyear law students practised finding, reading and applying caselaw, legislation, journal articles and other sources of law, and drafting documents such as office memoranda and heads of argument. A new LLB curriculum took effect in 2013 where the existing 
two Legal Skills modules and two Introduction to Law modules were integrated into two Jurisprudence modules. During the recent curriculum renewal process, some voices in the Faculty called for the re-introduction of the Legal Skills and Introduction to Law modules, with some calls that these modules be offered by the Department of Public Law or Procedural Law, and no longer by the Department of Jurisprudence. Arguably, the business-end of the (currently halted) curriculum renewal process had been dominated by an emphasis on the place and sequencing of modules instead of an overhaul of the content of law modules and the approach by which teaching should take place. When confronted with questions on how the CTFD was factored into the argument for the re-introduction of a stand-alone Legal Skills module, some argued that 'legal skills cannot be transformed'. In the remaining part of this article, we reflect on this statement and offer some tentative proposals on how to transform legal skills.

\section{Conclusion: The transformation/decolonisation of legal skills?}

Skills training and education on doctrine/theory should be integrated in the same modules; the skills required of lawyers and an implicit or explicit understanding of why the LLB is offered should be complemented in the same module - where do we see our graduates going; how do we understand the relationship between law and society; between legal education and legal practice. To have a standalone skills course that does not point out the value and limitations of legal skills may confuse students and may be counter-productive.

The legal skills required from law graduates will depend on a particular society's conception of legal education and how legal institutions function in that society. How a particular law faculty inculcates legal skills, will depend on that faculty's understanding of what lawyers do. A legal academic who is of the view that lawyers apply the law in a context-neutral, formulaic manner to solve discrete, insular 'legal' problems (as opposed to, for example, 'political' problems) and who is then tasked to teach legal skills, may well do so in a manner comparable to how Legal Skills was taught in the Law Faculty at the University of Pretoria until 2012. The lecturers in the Legal Skills modules made some attempt to sensitise law students to South Africa's socio-political and socio-economic context by, for example, requiring students to apply the Promotion of Equality and Prevention of Unfair Discrimination Act 4 of 2000 to hypothetical scenarios. However, the emphasis in those modules was 
on inculcating technocratic skills - how to summarise a court case, how to apply a court case to an analogous set of facts, how to apply a given Act to a novel set of facts, how to draft an office memorandum or letter of advice to a client or heads of argument, how to conduct a basic mock trial. The hypothetical legal practitioner who would require these skills would then be an attorney, applying the common law as developed and found in recent caselaw, or applying legislation or, in private practice, conducting some trial advocacy. Social justice-related legal work does not feature prominently, if at all, in this conception of what lawyers do. If a particular law faculty shifts in how it conceives of what lawyers do, the manner in which they address legal skills training may also shift. And if a particular society shifts in how it conceives of law and lawyers, different legal skills may become necessary. When talking of 'decolonising' legal skills, the implication would be that a particular society has also become decolonised - or else the current set of legal skills would still be valued and required. In this respect, the $\mathrm{CHE}$ accreditation panel report of the UP LLB is instructive. The UP Law Faculty was gently criticised for not preparing its graduates better for practice. To 'decolonise' legal skills in this context - in a society that has not been decolonised - may then well lead to an LLB that will not receive accreditation in the next round of LLB reviews. The skills that are currently valued then seem to be memorising, knowing the law, decent reading and writing skills, and a capacity for some critical analysis to apply legal knowledge to so-called 'real-life' problems (Campbell 2014; Stell \& Motala 1996; Whittle 2015). It then seems more apt to speak of 'transforming' legal skills in a South African society that is slowly transforming. Over time, the South African legal community could shift to valorise a more varied set of skills: not only the technocratic ability to read and analyse and apply legal principles to discrete, insular legal problems, but also, for example, empathy, a social conscience of South Africa's deep and systemic inequalities, having the ability to conduct difficult conversations, and so on.

If positivist or formalist legal education provides a neatly packaged, singlesolution educational experience, law clinics do the opposite. Law clinics rely on experiential learning, which in turn prepares students for the realities of practice (Amsterdam 1984). These realities arguably expose students to the problems faced by indigent clients, the vast majority of which would be African, and therefore in an implicit manner integrating a living law element into legal education. Teaching law in the context in which it operates indigenously - in South Africa, law as experienced and used by Africans - can bring about a transformational element to the education of 
prospective legal practitioners. Law clinics can provide diversity and a multicultural element to education (Vawda 2008). This may be true especially in instances when teachers in the formal LLB programme are not, or are having difficulty, embracing transformed/decolonised content. At an absolute minimum, and as an immediate short term measure, a compulsory Law Clinic module should be introduced into the UP LLB.

Taking a more long-term view, and if the transformation/decolonisation debate is understood to have potentially concrete outcomes, academic staff should reflect honestly and earnestly and engage in robust debate with each other and in the classroom on matters such as the purpose of legal education, to what end we employ classroom techniques, law's relationship to society, law's (in)ability to effect largescale societal transformation, the relationship between legal education and legal practice, how we conceive of "social justice" and a "socially just South Africa", the ethical and legal duties and responsibilities of law academics and practitioners in the face of daunting socio-economic inequalities, and so on.

We should spell out our own positions in the classroom, and invite debate on these contested meanings. (These questions should of course have been asked since 1994 at least). We will have different answers to these questions, depending on a particular lecturer's position - but we should demand honesty and accountability from one another. Depending on our answers to these questions, our conception of which skills should be inculcated in our students will differ, but it is proper to expose students to a variety of viewpoints and skills. The technocratic skills that are currently valorised in the Faculty are part of the set of skills required of any lawyer, but South Africa's socio-economic and socio-political context require other skills as well. If a particular lecturer is of the view that law has serious limits in facilitating large-scale societal transformation, which skills should then be inculcated in law students who are still interested in pursuing law as an academic discipline, and who would like to see a more socially just South Africa? If a particular lecturer views the organised legal profession as a potential impediment to societal transformation, which skills should be inculcated in law students to address these impediments? Demystifying the law is then a skill to be valorised, and can be achieved through the use of plain language when communicating about the law. Students' own lived experiences should be used in inculcating legal skills. It is probably already possible to establish some concrete principles on what a decolonised legal system will look like and which skills would be or should be valorised in such a system - a bigger emphasis on oral storytelling 
and communal problem-solving; and situation-sensitive solutions aimed at restoring harmony to the group instead of looking for solutions in written precedents.

\section{References}

Amsterdam, A.G. (1984). Clinical legal education - a 21st century perspective. Legal Education, 34: 612-616.

Campbell, J. (2014). The Role of Law Faculties and Law Academics: Academic Education or Qualification for Practice?. StelILR, 25:15-33.

Cardozo, M.T.A.L. (2012). Decolonising Bolivian Education: Ideology Versus Reality. In T. Griffiths \& Z. Millei (eds), Logics of Socialist Education: Engaging with Crisis, Insecurity and Uncertainty (p. 24).

Collins, P.H. (1991). On Our Own Terms: Self-Defined Standpoints and Curriculum Transformation. NWSA Journal 3(3367).

Delport, T. and Dladla, N. (2013). Rehumanising the Colonialities. (13-05-2013) Mail \& Guardian Online (https://mg.co.za/article/2013-05-13-rehumanising-thecolonialities Accessed 27 August 2019).

Dladla, N. (2012). Decolonising the University in South Africa - A Precondition for Justice. In: Peace and Security for African Development (pp. 160-174). Pretoria: Africa Institute of South Africa.

Freire, P. ([1970]/2003). Pedagogy of the oppressed, trans. Myra Bergman Ramos. New York: Continuum.

Himonga, C. \& Diallo, F. (2017). Decolonisation and Teaching Law in Africa with Special Reference to Living Customary Law. PER / PELJ, 20(2).

Mbembe, A. (2012). At the Centre of the Knot. Social Dynamics, 38(1).

McIntosh, P. (1982). Interactive Phases of Curriculum Revision. Working paper series. Wellesley College Center for Research on Women. In P.H. Collins, On Our Own Terms: Self-Defined Standpoints and Curriculum Transformation. NWSA Journal, 3(3367).

McLaughlin, J.M. \& Whatman, S.L. 2008. Embedding university perspectives in university teaching and learning: lessons learnt and possibilities for reforming/ decolonising curriculum. In R.W. Heber (ed), Indigenous education: Asia/Pacific (pp. 123-146). 
Modiri, J.M. 2013. Transformation, Tension and Transgression: Reflections on the Culture and Ideology of South African Legal Education. Stellenbosch Law Review, 24(3): 455.

Modiri, J.M. 2016. The Time and Space of Critical Legal Pedagogy. Stellenbosch Law Review, 27(3).

Motala, Z. 1996. Legal education in South Africa: Moving beyond the couch-potato model towards a lawyering skills approach: A case for a comprehensive course on legal research, analysis and writing. SALJ, 113: 695.

Nayar, P.K. 2015. Latin American Postcolonial Studies and Global Decolonization. In F. Coronil, Postcolonial Studies: An Anthology (p. 176).

Price, M. \& Ally, R. 2015. UCT Year in Review. University of Cape Town.

Sachs, A. 2008. A Gentle Provocation: A reply to Stu Woolman. In S. Woolman \& M. Bishop (eds), Constitutional Conversations (p. 37).

Siu, A., Desai, C. \& Ritskes, E. 2012. Towards the 'tangible unknown': Decolonization and the Indigenous future. Decolonization: Indigeneity, Education \& Society, 1(1).

Vawda, Y.A. 2008. 'But, where is the halaal food?' An appraisal of diversity teaching in clinical law programmes in South African clinics. JJS Special Issue (pp. 87, 88).

Visser, D. 1989. The Legal Historian as Subversive (or Killing the Capitoline Geese). In Essays on the History of Law.

wa Thiongo, N. 1986. Decolonising the mind: The politics of language in African literature. Heinemann Educational Books.

Whittle, B. 2015. Law Deans and Legal Profession to Discuss Refinement of LLB. 12: 12.

Zegeye, A. \& Vambe, M. 2011. Close to the Source: Essays on Contemporary African Culture, Politics and Academy. Routledge. 